\title{
Forms in Space. AR Experiences for Geometries of Architectural Form
}

\author{
Marta Salvatore \\ Leonardo Baglioni \\ Graziano Mario Valenti \\ Alessandro Martinelli
}

Abstract

Learning through the direct experimentation of models, in their variety of manifestations and hybridizations that we know today, is undoubtedly a very powerful aid in the acquisition of knowledge. Specifically on architectural form, this aid is even more important, because it helps not only to understand the form of existing architecture, but even more to imagine and design new ones. The research here presented, focusing on this double objective, cognitive and creative, proposes and experiments new ways of integrating and interacting with heterogeneous models - both physical and virtual - conceived for a scenario of musealization of the architectural form. A place where the user interacts and experiences the properties and peculiarities of form, in perceptive continuity between real and virtual space.

Keywords

descriptive geometry, form, digital model, augmented reality, projected augmented reality.

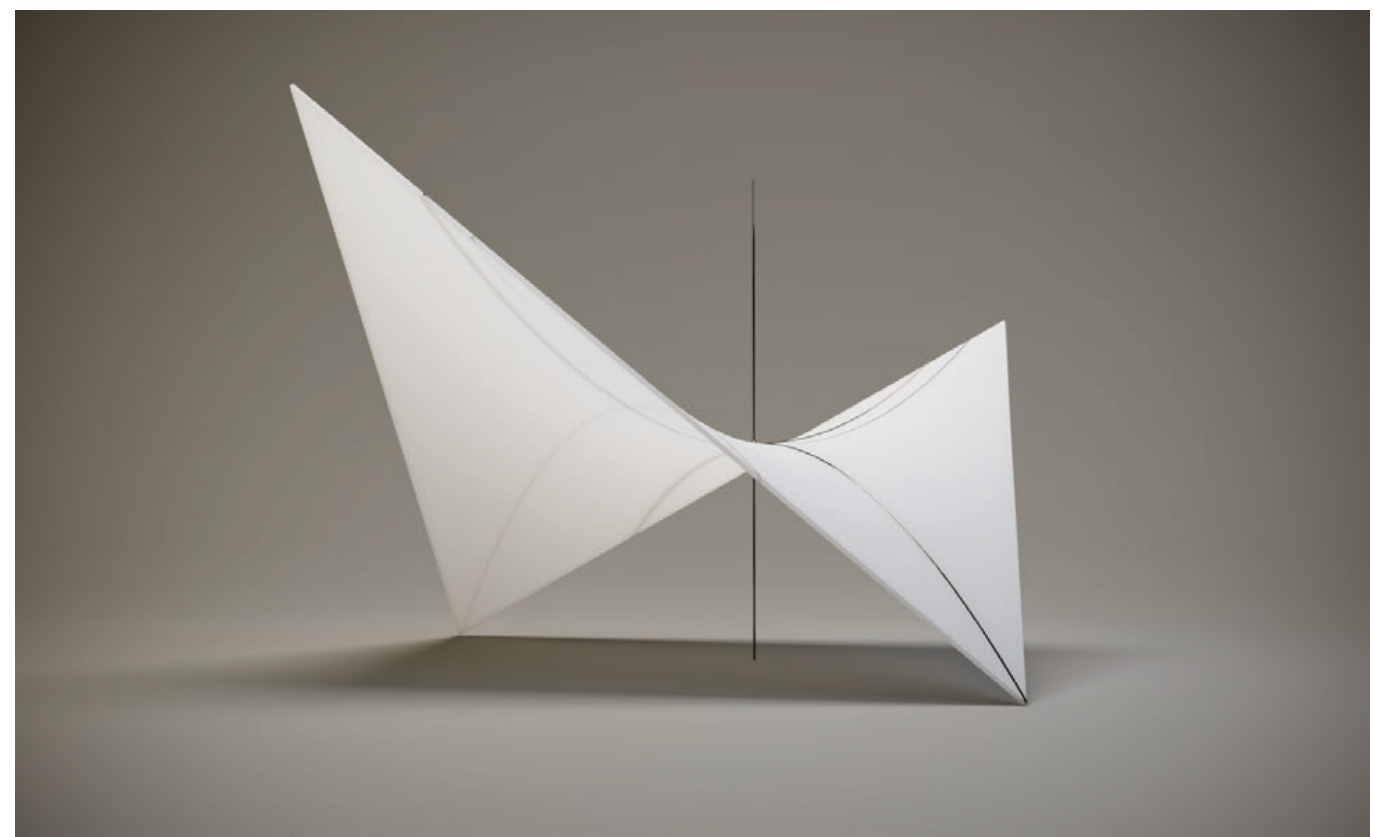


The proposed experimentation intends to clarify, through Augmented Reality applications, the relationship between the properties of geometrical form and the architectural project.This idea is part of a larger project of the musealization of form aimed at investigating the close relationship existing between the geometric properties of form, its exploration through drawing and the architectural project.

The concept of 'model' is at the basis of this expositive idea. The tools to be used are those of synthetic geometry, which studies and communicates the form through drawing, i.e. using visual synthetic languages. The synthetic method is founded right on the 'constructive' character of descriptive geometry. This character is evident when referring to the geometry of space or of extension - using a definition given by Gino Loria in the early twentieth century - as the science that deals, in abstract terms, with repeatable procedures that can be reproduced in physical reality [Loria 1935, p. 77]. Therefore, the idea of construction, understood as a generative process of the form, is the privileged object of the exhibition that the museum intends to communicate, in terms of pure geometric speculation and in relation to the classical and contemporary repertoire of architectural projects. An idea that transpires, citing one of the most famous examples in architecture, from the formwork traces left on the concrete of the ruled surfaces in several works by the masters of the modern movement, which recount the evidence of the reasons of the form.

\section{Towards a Museum of Form}

Today, the possibility of operating in the virtual three-dimensional space of a computer has extended the experimentation field about the form, permitting to derive, with a synthetic method, properties that were impossible to investigate through the two-dimensional graphical representation. Thus, many geometric problems find effective synthetic solutions thanks to the use of skewed curves, curved or double curvature surfaces, unthinkable to employ until the last century, opening the way to new possible research developments [Migliari 20 I2, pp. I4-42].Therefore, the three-dimensional digital representation renews the heuristic value of the 'construction' using the synthetic method for resolving geometrical problems, allowing the geometric control of properties that find application in different areas of design experimentation.

While three-dimensional representation expanded the cognitive possibilities around the form by the direct interaction with them, it also significantly contributed to promote its knowledge. In fact, the visual languages that today communicate the form describe, in exact and unambiguous way, the lines and surfaces properties. This twofold capability of the synthetic method, cognitive on the one hand, and communicative on the other, was the starting point that generated the idea of a musealization project of the form.

The idea at the basis of this project consists in describing the properties of lines and surfaces, through theoretical and speculative models, and to explain the relationships between these geometries and the form in the real space (natural or anthropic) but also in the ideal space, where the design idea originates.

The communication of form through the models belongs to the tradition of the mathematics and geometry schools since the early nineteenth century $[\mathrm{I}]$. In continuity with this tradition, a dynamic use of these models is proposed, where chalk and stretched wires are replaced by three-dimensional representations made with contemporary forms of digital representation. Digital, physical models and their related hybridization, become a vehicle for the dynamic interaction and, at the same time, a privileged platform where the public can experiment and understand its design implications. In this context, Augmented Reality and Projected Augmented Reality applications play a role of particular interest due to their communicative potential.

The exhibition space has been conceived as a didactic laboratory on the one hand and as a research laboratory on the other. An implementable interactive platform capable of hosting a wide repertoire of shapes: lines, polyhedra and surfaces with which to interact through their respective properties. Geometrical, analytical and differential, these properties allow to identify, from time to time, the categories of affine surfaces and to know their genesis, symmetries, remarkable sections, etc. [Migliari 2009]. In addition, to show the geometric properties of the figures, the same models are intended to describe the morphological variety that can be achieved in design by using the same surface in different ways, according to its different portions (fig. I). 
Fig. I. Hyperbolic paraboloid and its sections in the Los Manantiales Restaurant by Fellx Candela (Mexico City, 1956)
Fig. 2 Interactive model of the AR application for the the exploration of the hyperbolic paration properties.

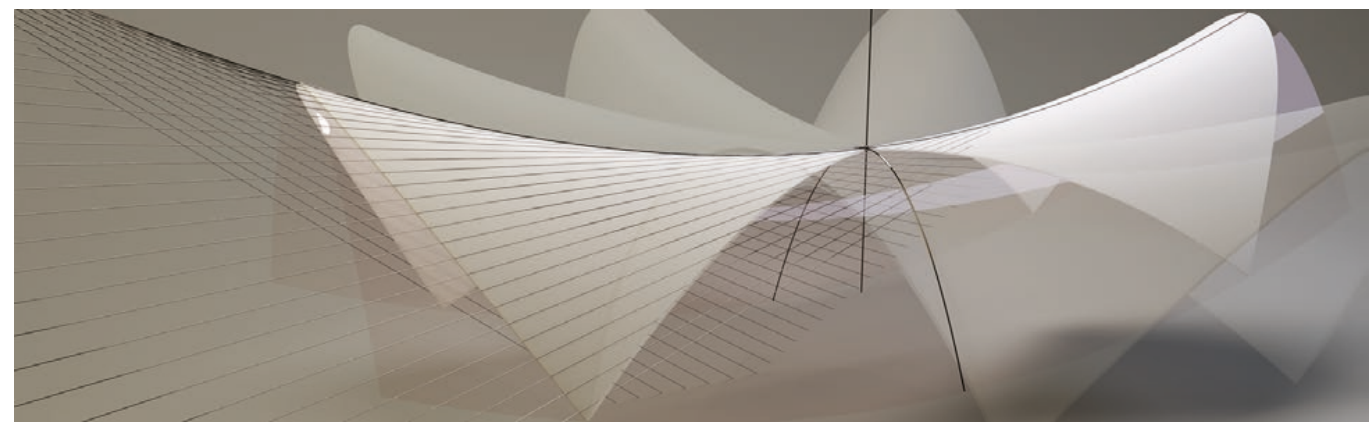

Therefore, the proposed models constitute an expositive prototype, with which to experiment the possibility of redesigning new ways of communicating the form that permit its three-dimensional exploration, revealing its peculiar characteristics. However, at the center of the exhibition project we do not find the final result, namely a surface or a curve, but the generative process that led to that particular spatial configuration, in other words its construction. The construction, understood as an existential demonstration of the form, is the foundation of the synthetic approach, i.e. graphic approach, with which descriptive geometry operates, univocally characterizing the modus operandi of architects.

\section{Augmented Reality Experimentations}

The extreme simplicity and technological advances implemented in everyday tools, such as smartphones, tablets, laptops, have made it possible to spread AR-technologies in every level of education, from primary school to university. The advantage of not needing for additional hardware such as visors or helmets typical in the VR field, makes AR-technologies particularly suitable for applications in numerous and heterogeneous sectors of scientific and humanistic knowledge [Voronina et al. 20 19]. Many studies show that AR plays a fundamental role in pedagogical applications today, although their potential is still partially explored [Burton et al. 20 I I, pp. 303-329 4; Wu et al. 20 I3, pp. 4l-49].

As part of the project aimed at the realization of a museum of the form, the experimentation of $A R$ is one of the principal models through which to experience the properties of the form and the effects that these transfer into the architectural project. This type of representation offers the possibility of direct interaction with the digital model, allowing to operate with the abstract entities typical of the geometry of space: one and two-dimensional forms, that otherwise could not be realized in the real world, can be controlled in a representation on the edge between virtual and physical reality. The user operates with the form in order to understand its properties, that reveal their evidence in the finished form but, even before, in the generative process that led to it. According to this double need of fruition, the application focuses its attention on the representation of two states of the form: its construction process and its final configuration. The idea of representing generative processes and final configurations concerns both the pure geometric form and the one applied to the project. Depending on its geometric properties, this is declined in different ways, giving rise to a heterogeneous and morphologically varied repertoire of architectures, all referable to the same formal matrix.




Fig. 3 Geometrical genesis of the Palmira Chapel (Felix Candela, 1958) starting by the hyperbolic paraboloid (n) application.

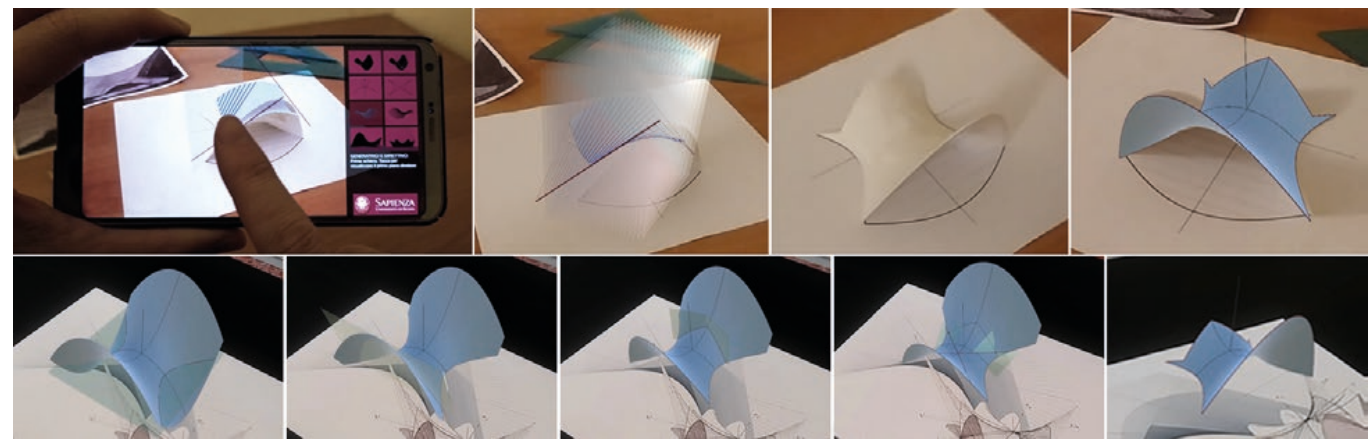

From a strictly operational point of view, through the application the user can retrace the generative process of construction of the pure geometrical form, recognizing the properties in its final configuration and understanding how these properties are reflected in the architectural form conditioning the aesthetic and constructive aspects. It will therefore be possible to enjoy the model through the application by choosing the direction of the path to follow: from the geometric world to the architectural one or inferring the geometric properties of the form starting from its applications. This double way of reading favors the double objective: increasing awareness and ability regarding the geometric control of lines and surfaces feeding the education in geometry; increasing the knowledge by operating in space with the form, through a journey from the known to the unknown that leads to the derivation of new properties of figures [2]. The experimentation, still in progress, is oriented around the development of prototypal AR models, like that of the hyperbolic paraboloid and its applications (fig. 2). Developed in Unity 3D environment, the model is activated in virtual space through an image or a threedimensional model (used as a Target), which provides the surface in different configurations resulting from its geometrical genesis (a skew quadrilateral or a saddle). This virtual surface can be explored by the user, who can classify it in different ways by combining its properties from a speculative geometric approach or from its applications in architecture. For example, from a synthetic point of view, this can be explored as a ruled surface whose generatrices and directrices are activated by contact with the surface itself. Otherwise, it can be considered as a second-order algebraic surface of which to derive the axes and symmetry planes and, sliding in contact with it, remarkable sections generically oriented in space. Moreover, it can also be classified from the point of view of differential geometry by ranging the osculating circles of principal curvatures. However, it is also possible to interact with the surface in question by sectioning it with notable planes, obtaining portions of surfaces that combine with each other, giving rise to a various morphological design repertoire, as in the case of some projects by Felix Candela (fig. 3).

In addition to this AR model type, the experimentation foresees that shape analysis is also enjoyed through hybrid models Projected AR type, in which 3D prints of surfaces are augmented in their information content through the video projection of their remarkable properties (fig. 4). In this case the physical model, reproduced with rapid prototyping techniques, is used for activating the AR projections, and for supporting projections themselves, which allow the user to learn the properties of the shape by directly interacting with the physical model.

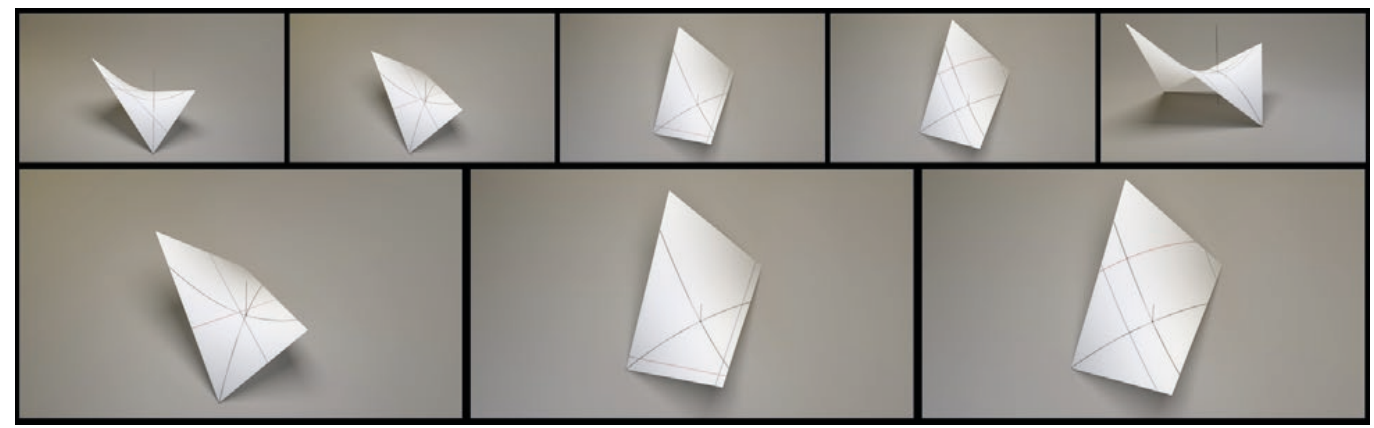




\section{Conclusions}

Representation has always had a central role in the genesis of the architectural project. The graphical exercise has always been an immediate expression of design thinking and a tool for the progressive elaboration of an idea that is nourished and grows through the repetition of its own representation, in a virtuous circle that accompanies the entire design process. Exploration of the form through drawing, namely by its construction, leads to increasing knowledge by passing from the known to the unknown, researching new properties of shape to derive. In this regard, the heuristic value of representation reveals its maximum expressive potential. Thus, the three-dimensional representation and its exploration constitutes a flywheel for research into architectural form, revealing its geometrical motivations in virtual space. The proposed experimental models, developed through AR and Projected AR experiences, describe the construction of form and show its properties, illustrating the potential of aggregation deriving from them. Potentialities that generate a wide and heterogeneous morphological repertoire of which several architectural projects are the expression.

\section{Notes}

[I]The project is inspired by the collections of mathematical models made in Europe between the second half of the nineteenth century and the early twentieth century. These exhibitions were aimed at "showing remarkable properties concerning the research topic investigated and showing some results that were progressively achieved in different fields of 'pure' and 'applied' mathematics: Descriptive and Projective Geometry, Analytical Geometry, Algebraic Geometry" [Palladino 2008, p. 3 I]

[2] The didactic purposes also include the implementation of learning tasks to verify understanding [Kaufmann 2003, pp. 339-345].

[3] The idea of knowledge as a passage from the known to the unknown is a founding principle of descriptive geometry. It was introduced by Monge in the first pages of his Géométrie Descriptive, where he illustrated its objectives and principles; today, in the field of digital representation, it still appears highly relevant [Monge 1798, p. 2].

\section{References}

Burton Erin Peters, Frazier Wendi, Annetta Leonard, Lamb Richard, Cheng Rebecca, Chmiel Margaret (201 I). Modeling Augmented Reality Games with Preservice Elementary and Secondary Science Teachers. In Journal of Technology and Teacher Education, 19 (3), pp. 303-329.

Kaufmann Hannes, Schmalstieg Dieter (2003). Mathematics and geometry education with collaborative augmented reality. In Computers \& Graphics, 27, pp. 339-345

Loria Gino (1935). Metodi matematici. Milano: Hoepli.

Migliari Riccardo (2009). Geometria descrittiva.Vol. II. Novara: CittàStudi Edizioni.

Migliari Riccardo (2012). La geometria descrittiva nel quadro storico della sua evoluzione dalle origini alla rappresentazione digitale. In Carlevaris Laura, De Carlo Laura, Migliari Riccardo (ed.). Attualità della geometria descrittiva. Roma: Gangemi, pp. I 5-42.

Monge Gaspard (1798). Géométrie descriptive. Paris: Baudouin.

Palladino Nicola, Palladino Franco (2008). I modelli matematici costruiti per l'insegnamento delle matematiche superiori pure e applicate. In Ratio Mathematica, 19, pp. 3 I-88.

Voronina V. Marianna, Tretyakova Zlata, Krivonozhkina Ekaterina G., Buslaev Stanislav I., Sidorenko Grigory G. (2019). Augmented Reality in Teaching Descriptive Geometry, Engineering and Computer Graphics - Systematic Review and Results of the Russian Teachers' Experience. In EURASIA Journal of Mathematics, Science and Technology Education, I5 (I2), pp. 2- I7.

Wu Hsin-Kai, Lee Silvia Wen-Yu, Chang Hsin-Yi, Liang Jyh-Chong (2013). Current status, opportunities and challenges of augmented reality in education. In Computers \& Education, 62, pp. 4 I-49.

Authors

Marta Salvatore, Dept of History, Representation and Restoration of Architecture, Sapienza University of Rome, marta.salvatore@uniromal .it Leonardo Baglioni, Dept of History, Representation and Restoration of Architecture, Sapienza University of Rome, leonardo.baglioni@uniromal it Graziano Mario Valenti, Dept of History, Representation and Restoration of Architecture, Sapienza University of Rome, grazianomario.valenti@uniromal .it Alessandro Martinelli, Dept of History, Representation and Restoration of Architecture, Sapienza University of Rome, alessandro.martinelli@uniromal .it 
